\title{
Evaluation of the Effects of Rheumatoid Arthritis on the Hard and Soft Tissue Components of the Temporomandibular Joint by Using Magnetic Resonance Imaging \\ Hajer Ibrahem Abdulla
}

B.D.S,M.Sc,C.O.M(USA). Oral Medicine Department, College of Dentistry, Al-Mustansiriya University Ameer N. Kubba

B.D.S,Oral Medicine Department ,College of Dentistry, Al-Mustansiriya University

Mohammed M.J. Al-khalissy

Consultant Radiologist ,Al-Kadhmyia Teaching Hospital

\begin{abstract}
Background : Magnetic resonance imaging (MRI) has been used to visualize the destructive effect of the rheumatoid arthritis ( RA) within the body joints, while Temporomandibular joint is often to be neglected.

Aim of the study: to observe the hard and soft tissue changes as well as the clinical involvement that may affect the TMJ in patients with longstanding RA.

Patients and methods: 42 patients ( 84 TMJ'S), with mean age of (40.6 years) ranged from (28 to 63 ) years were divided into 2 groups; study (30) and control (12), all study group subjects consisted of patients with confirmed RA according to the criteria of American College Of Rheumatology (1987).Both groups had been examined clinically (at Al-Mustansiriya University/College of Dentistry) and with MRI (at the MRI unit at Al-Kadhmyia Teaching Hospital) in both sagital and coronal planes (open and close mouth) by the use of proton density and T2 weighted protocols.

Results : The clinical involvement was present within (73.3\%) of the study sample as the joint's sounds were the predominant feature $(80 \%)$, masticatory muscle tenderness tenderness $70 \%$, pain during function $58 \%$, morning stiffness $36.6 \%$, deviation $43.3 \%$ while open bite was present in two cases (6.6\%) ,33.3\% of the RA patients had at least 3 clinical involvements, $26.6 \%$ had at least 2 clinical involvement, uni-lateral involvement was present in $30 \%$ of RA patients, 5 subjects had only right side involvement and 4 patients had only left side involvement while bilateral involvement was present in $50 \%$ of RA patients. The mouth opening was significantly lowered $(\mathrm{P}<0.01)$ when compared with the control group.MRI findings were present in $80 \%$ of the study sample which led to a significant difference statistically when compared with the control group, the most common finding was the condylar head erosion (CHE), complete condylar destruction (score 4) was found in 2 RA patients, internal derangement 73.3\%, meniscus perforation $73 \%$, joint effusion $70 \%$, increased joint space $66.6 \%$, and osteophytes formation $60 \%$, unilateral involvement was present in $53.3 \%, 5$ subjects had right involvement only, and 7 subjects had left side involvement, while bilateral involvement was present in $46.7 \%$.
\end{abstract}

Key Words: Temporomandibular Joint, Rheumatoid Athritis, Magnatic Resonance Imaging , Condylar Head Erosion.

\section{INTRODUCTION}

Rheumatoid arthritis is a chronic inflammatory disease characterized by joint swelling, joint tenderness, and destruction of synovial joints, leading to severe disability and premature mortality.(1).

This inflammatory response particularly affects small joints of the upper and lower extremities including TMJ and it often leads to the deterioration and eventual destruction of articular cartilage and juxta-articular bone, as well as to an inflammatory process surrounding tendons, all of which frequently result in deformities of the affected joints ${ }^{(7)}$.

Temporomandibular joints afflicted with RA may produce pain, joint stiffness, difficulties in opening the mouth, and open bite. In severe cases of temporomandibular joint disorders, masticatory movement may be hampered (2).

Despite the superior resolution of CT and limited visualization of cortical bone by MRI, most osseous pathology is accurately depicted. Intra-articular abnormalities are readily visible on MRI images, providing further information not available with other imaging modalities (3), plus direct visualization of the disk afforded by MRI is a distinct advantage over arthrography.

\section{PATIENTS AND METHODS}

This research was carried out on a sample of 42 patients (14 males and 28 female) 84 TMJ's $71.5 \%$ of them were previously diagnosed with rheumatoid arthritis according to the revised criteria of ACR (American College of Rheumatology) in 2010 and they were referred from the Rheumatology Unit in Al-kadhmyia Teaching Hospital (all the patients has a medical record within the mentioned hospital) with no other systemic diseases which might have affected the MRI findings .They were divided into two groups (study and control) both groups were clinically evaluated on a dental chair at the Postgraduate Clinic in Al-Mustansirya University/College of Dentistry -Oral Medicine Department regarding the mouth opening, joints sounds, muscle tenderness, morning stiffness, feeling of pain,pain during movement, and deviation, then the two groups were again examined 


\section{Oral Diagnosis}

radiographicaly by MRI at Al-Kadhmyia Teaching Hospital / MRI Unit done by using proton density T2 weighted protocols in both sagital and coronal plane with bilateral $6 \times 8 \mathrm{~cm}$ surface coil placed over the patient's head, each subject was examined -regarding MRI- in two positions, open and the closed mouth.

\section{RESULTS}

\section{THE CLINICAL FINDINGS}

The clinical involvement was present within $73.3 \%$ (see table-1-) of the study group subjects It was found that the mean of the non-assisted mouth opening in the RA group was $3.913 \mathrm{~mm}$ while in control group $4.783 \mathrm{~mm}$. The difference was statistically highly significant $(\mathrm{P}<0.05)$ (see table-2-), while the most important clinical finding was that the joint sounds $80 \%$, masticatory muscle tenderness $70 \%$, pain during function $58 \%$,morning stiffness $36.6 \%$, deviation $43.3 \%$ while open bite was present in two cases (6.6\%), (see table -3-) again all the results were highly significant when compared to the control group ( $\mathrm{P}<0.05), 33.3 \%$ of the RA patients had at least 3 clinical involvements , $26.6 \%$ had at least 2 clinical involvement.

Table 1: Percentage of the clinical involvement within the study \& control group

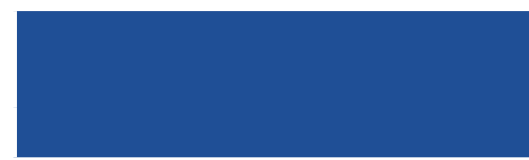

Clinical Involvement

\begin{tabular}{|c|c|}
\hline \multicolumn{2}{|c|}{$\begin{array}{c}\text { Study Group } \\
\text { Sum }=60\end{array}$} \\
\hline No. & $\%$ \\
\hline
\end{tabular}

44

\begin{tabular}{|c|c|}
$\begin{array}{c}\text { Control Group } \\
\text { Sum }=24\end{array}$ \\
\hline No. & $\%$ \\
\hline
\end{tabular}

8

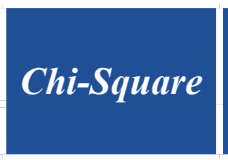

53.00
P-Value

$\mathrm{P}<0.01^{*}$

Table 2: The mean of the non-assisted mouth opening in both study and control group

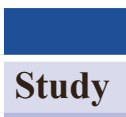

Control

\begin{tabular}{|c|}
\hline No. \\
\hline 30 \\
\hline 12 \\
\hline
\end{tabular}

\begin{tabular}{|c|}
\hline Mean \\
\hline 3.913 \\
\hline 4.783 \\
\hline
\end{tabular}

\begin{tabular}{|c|}
\hline SD \\
\hline 0.331 \\
\hline 0.483 \\
\hline
\end{tabular}

\begin{tabular}{|c|}
\hline T-Test \\
\hline 5.492 \\
\hline
\end{tabular}

\begin{tabular}{|c|}
\hline P-Value \\
\hline $\mathrm{P}<0.01^{*}$
\end{tabular}

Table 3: clinical involvement within the study group compared to the control group

\begin{tabular}{|l|}
\hline \\
\hline Normal muscle tone \\
\hline Masticatory muscle tenderness \\
\hline Normal joint sounds \\
\hline Joint Sounds \\
\hline Normal muscle tone \\
\hline Masticatory muscle tenderness \\
\hline Patients without morning \\
stiffness \\
\hline Morning stiffness \\
\hline No pain on palpation \\
\hline Pain on palpation \\
\hline No Pain during movement \\
\hline Pain During movement \\
\hline Normal mouth opening without \\
deviation \\
\hline Deviated mouth opening \\
\hline Normal occlusion \\
\hline Open bite \\
\hline
\end{tabular}

\begin{tabular}{|c|c|}
\hline \multicolumn{2}{|c|}{$\begin{array}{c}\text { Study } \\
\text { Sum }\end{array} \mathbf{3 0}$} \\
\hline No. & $\%$ \\
\hline 9 & 30 \\
\hline 21 & 70 \\
\hline 12 & 20 \\
\hline 48 & 80 \\
\hline 9 & 30 \\
\hline 21 & 70 \\
\hline 11 & 36.7 \\
\hline 19 & 63.3 \\
\hline 18 & 30 \\
\hline 42 & 70 \\
\hline 50 & 33.3 \\
\hline 10 & 16.6 \\
\hline 17 & 56.7 \\
\hline 13 & 43.3 \\
\hline 28 & 92.9 \\
\hline
\end{tabular}
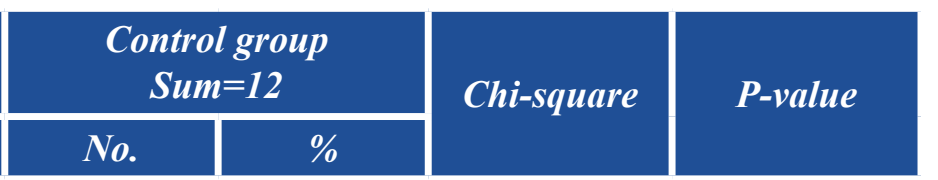

\begin{tabular}{|c|c|}
\hline 10 \\
\hline 18 \\
\hline 6 \\
\hline 10 \\
\hline 2 \\
\hline 10 \\
\hline 2 \\
\hline 18 \\
\hline 6 \\
\hline 23 \\
\hline 1 \\
\hline 12 \\
\hline 0
\end{tabular}

\begin{tabular}{|c|c|}
\hline 83.3 \\
\hline 16.7 \\
\hline 75 \\
\hline 25 \\
\hline 83.3 \\
\hline 16.7 \\
\hline 83.3 \\
\hline 16.7 \\
\hline 75 \\
\hline 25 \\
\hline 75 \\
\hline 4.16 \\
\hline 100 \\
\hline 0.0 \\
\hline 100 \\
\hline
\end{tabular}


uni-lateral involvement was present in $30 \%$ of RA patients. Although there was a difference regarding patients, 5 subjects had only right side involvement the involvement between the right and the left joint and 4 patients had only left side involvement while but statistically was considered as non-significant.

bilateral involvement was present in $50 \%$ of RA

Table 4: clinical involvement in a RT. and LT. TMJ pattern

\begin{tabular}{|l|c|c|c|c|c|}
\hline \multicolumn{1}{|c|}{ Clinical involvement } & $\boldsymbol{R}$ T. joint & LT. joint & Chi square & P value & \multicolumn{1}{|c|}{ SIG } \\
\hline Pain on palpation of TMJ & 20 & 22 & 0.903 & 0.311 & NS \\
\hline Joint sounds & 5 & 4 & 1.63 & 0.075 & NS \\
\hline Pain during movement of the TMJ & 5 & 5 & 0.38 & 0.38 & NS \\
\hline deviation & 7 & 6 & 0.42 & 0.333 & NS \\
\hline Muscle tenderness & 10 & 11 & 0.93 & 0.32 & NS \\
\hline
\end{tabular}

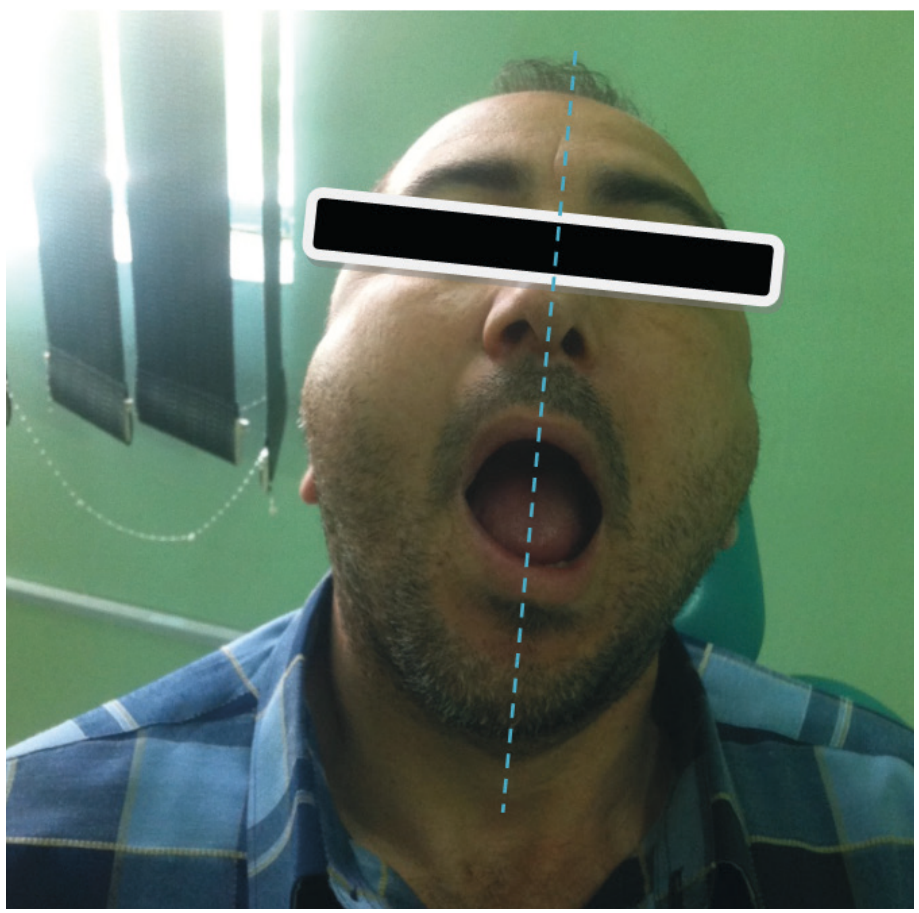

Figure (2): Deviation during maximal mouth opening(to the left)

Table (5): percentage of the MRI findings involvement within the study and control groups

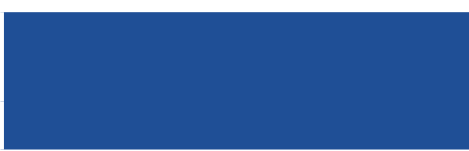

\begin{tabular}{|l|l|}
\hline \multicolumn{2}{|c|}{$\begin{array}{c}\text { Study group } \\
\text { Sum }=60\end{array}$} \\
\hline No. & $\%$ \\
\hline
\end{tabular}

MRI involvement

48

80

\begin{tabular}{|c|c|}
\hline $\begin{array}{c}\text { Control group } \\
\text { Sum=24 }\end{array}$ \\
\hline No. & $\%$ \\
\hline
\end{tabular}

8

\section{The MRI findings}

MRI findings was present in $80 \%$ of the study sample which led to significant difference statistically when compared with the control group $(\mathrm{P}<0.05)$ (see table-5-), the most common finding was the condylar head erosion (CHE), complete condylar destruction (score 4) was found in 2 RA patients (see fig.1), internal derangement $73.3 \%$, meniscus perforation $73 \%$, joint effusion $70 \%$, increased joint space $66.6 \%$, and osteophytes formation $60 \%$, again all findings were highly significant $(\mathrm{p}<0.05)$ when compared to the control group.(see table -6-) . Unilateral involvement was present in $53.3 \%, 5$ subjects had right involvement only, and 7 subjects had left side involvement, while bilateral involvement was present in $46.7 \%$. There was no statistical difference (nonsignificant ) between the right and left TMJ's MRI findings involvement when compared together . (see table 7)

Table (6) : MRI findings involvement findings in both study and control group compared to each other

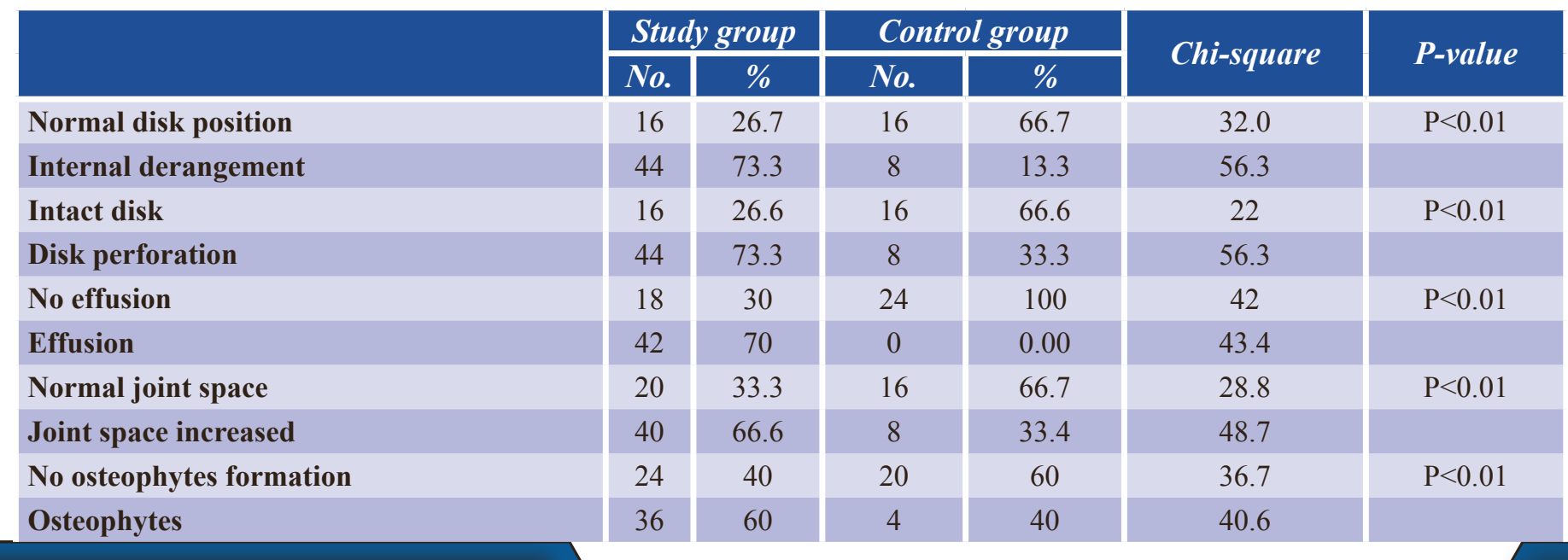




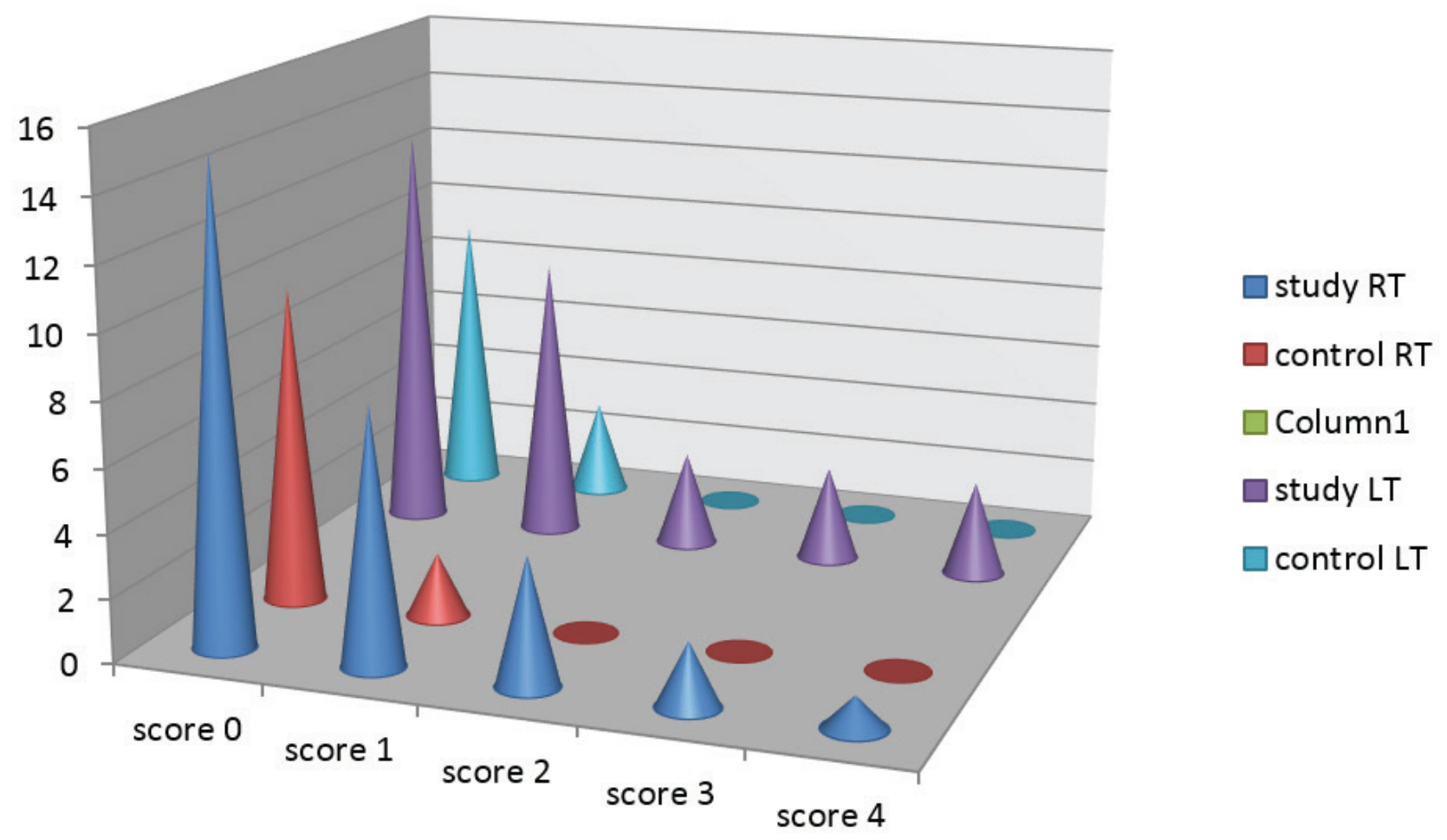

Figure 1: Condylar Head Erosion involvement in both study and control group (RT. \& LT pattern )

Table 7: MRI findings involvement in a RT. LT. TMJ involvement
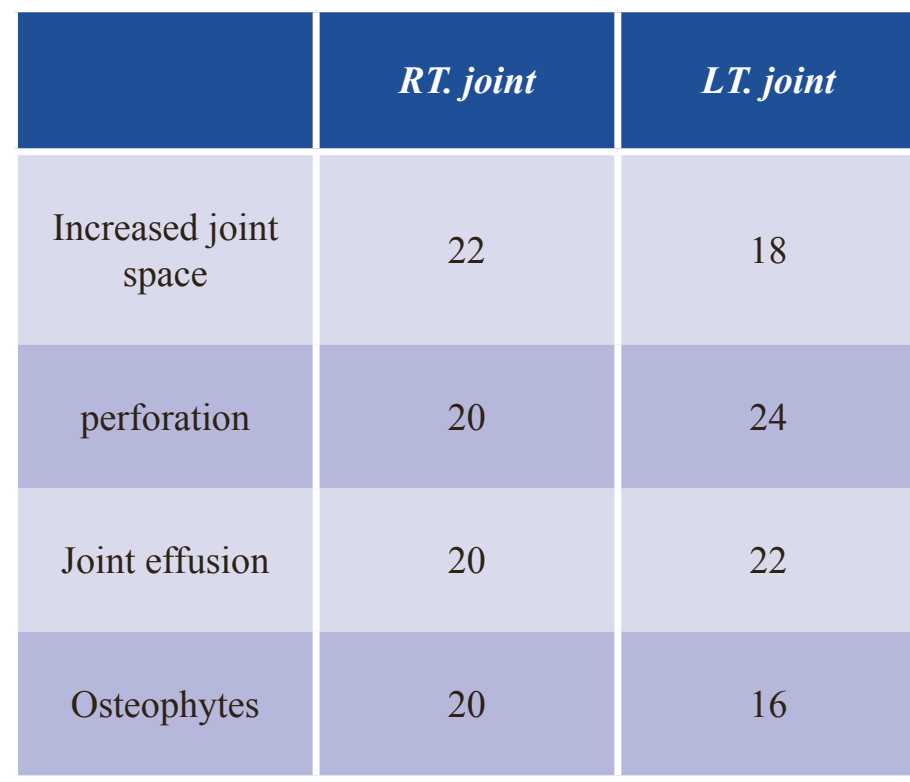

\section{DISCUSSION}

The temporomandibular joint (TMJ) may be affected in many rheumatic diseases especially rheumatoid arthritis ${ }^{(7)}$.but the mentioned joint is often neglected during studies and clinical practice In the current study among rheumatic diseases rheumatoid arthritis is the one to be investigated regarding it's role in the clinical and radiographic picture presentation of disability of the TMJ .

It was found that the incidence of RA was more in females than males and that was in agreement with other studies like (Lin YC, 2007) ${ }^{(6)}$ and

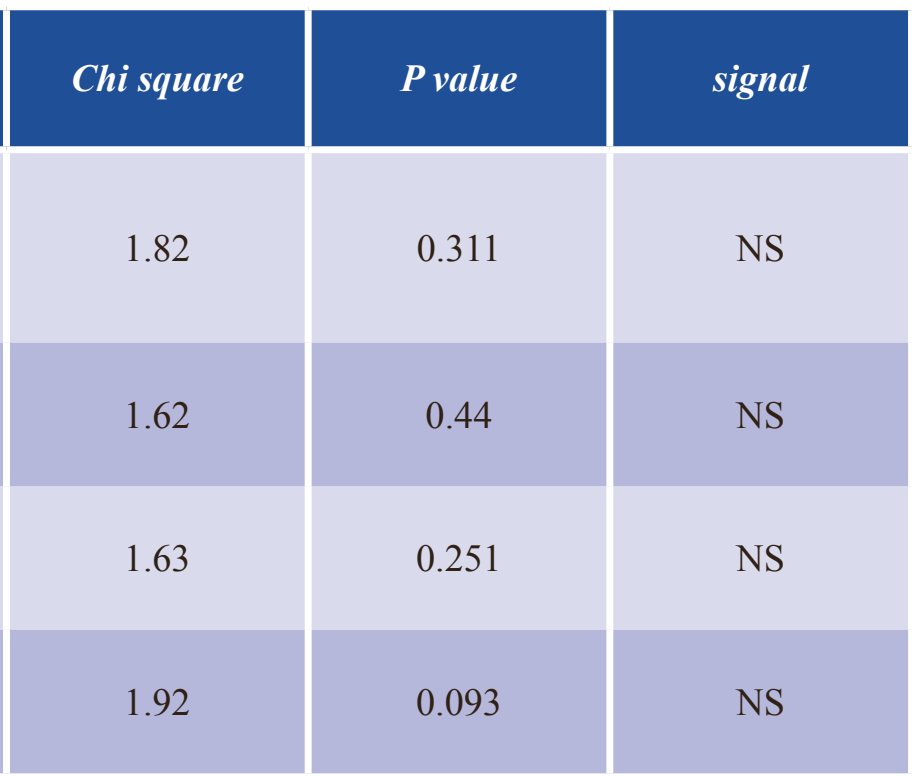

with (Lipisky 1998) $)^{(7)}$. The age range (45.6 years) ranged from (28 to 63) years and the duration of the disease was (20.6 years) and its effect upon RA subjects coincided with the criteria of RA according to British Society of Rheumatology ,2008. ${ }^{(3)}$, and other articles ${ }^{(6,9) .}$

The clinical involvement was present within $(73.3 \%)$ of the study subjects while joint sounds was considered the most predominant feature and that was in agreement with other previous studies $(5,6,9)$.

While the MRI findings involvement was present 
within (80\%) of the study group subjects, CHE was considered the most predominant feature and that was in agreement with other previous studies ${ }^{(11,12)}$.

All the recorded clinical and MRI findings were in agreement with other previous studies ${ }^{(1.2 .45 .9 .10)}$, but in different percentages and that may be due to the selection of the sample regarding the age, gender distributions,method used in the measurement, and the type of radiographic aid.

\section{CONCLUSION}

MRI is an excellent diagnostic aid of the TMJ in patients with RA The clinical and radiographic findings in the RA group were much more than that in the control group, but the changes are not always bilateral, a significant correlation was found between the extent of MRI findings and the duration RA disease.

\section{REFERENCES}

1. Aletaha D, Neogi T, Silman AJ, Funovits J, FelSon DT, Bingham CO, et al. 2010 rheumatoid arthritis classification criteria: an American College of Rheumatology/European League against Rheumatism collaborative initiative. Arthritis Rheum 2010; 62: 2569-2581.

2. Aliko A, Ciancaglini R, Alushi A, Tafaj A, Ruci D. Temporomandibular joint involvement in rheumatoid arthritis, systemic lupus erythematosus and systemic sclerosis. Int J Oral Maxillofac Surg. 2011;40(7):704-709.

3. British Society for Rheumatology. Clinical Guidelines: Rheumatoid Arthritis. Available from: British Society for Rheumatology. Last accessed on: 2008 July 30.

4. Helenius LM, Tervahartiala P, Helenius I, Al-Sukhun J, Kivisaari L, Suuronen R, Kautiainen H, et al. Clinical, radiographic and MRI findings of the temporomandibular joint in patients with different rheumatic diseases. Int J Oral Maxillofac Surg. 2006;35(11):983-989.

5. Larheim TA, Smith HJ, Aspestrand F. Rheumatic disease of the temporomandibular joint: MR imaging and tomographic manifestations. Radiology 1990; 175: 527-531.

6. Lin YC, Hsu ML, Yang JS, Liang TH, Chou SL, Lin HY. Temporomandibular joint disorders in patients with rheumatoid arthritis. J Chin Med Assoc. 2007;70(12):527534.

7. Lipsky PE. Rheumatoid arthritis. In: Wilson JD, Braunwald E, Isselbacher KJ et al., eds. Harrison's principles of internal medicine. 14th ed. New York: McGraw-Hill; 1998: 1880-8.

8. Neveen Ahmed, 1 * Hamid Masoud Mustafa, 2 Anca Irinel Catrina, 3 and Per Alstergren Impact of Temporomandibular Joint Pain in Rheumatoid Arthritis, Published online Dec 9, 2013. doi: 10.1155/2013/597419, Mediators,Inflamm. 2013; 2013: 597419.

9. Ozcan I, Ozcan KM, Keskin D, Bahar S, Boyacigil S, Dere H. Temporomandibular joint involvement in rheumatoid arthritis: correlation of clinical, laboratory and magnetic resonance imaging findings. B-ENT. 2008;4(1):19-24.

10. Suenaga S, Ogura T, Matsuda T, Noikura T. Severity of synovium and bone marrow abnormalities of the temporomandibular joint in early rheumatoid arthritis: role of gadoliniumenhanced fat-suppressed T1-weight spin echo MRI. J Comput Assist Tomogr 2000; 24: 461-465.

11. Voog U1, Alstergren P, Eliasson S, Leibur E, Kallikorm $\mathrm{R}$, Kopp S.Progression of radiographic changes in the temporomandibular joints of patients with rheumatoid arthritis in relation to inflammatory markers and mediators in the blood. Acta Odontol Scand. 2004 Feb;62(1):7-13.

12. Yilmaz HH, Yildirim D, Ugan Y, Tunc SE, Yesildag A, Orhan $\mathrm{H}$, Akdag C. Clinical and magnetic resonance imaging findings of the temporomandibular joint and masticatory muscles in patients with rheumatoid arthritis. Rheumatol Int. 2012;32(5):1171-1178.

\section{Submit your research}

\section{To publish your research you can send it |} via e-mail to:

- submit@iraqidentaljournal.com Taking into consideration the guidlines for authors (page II) 